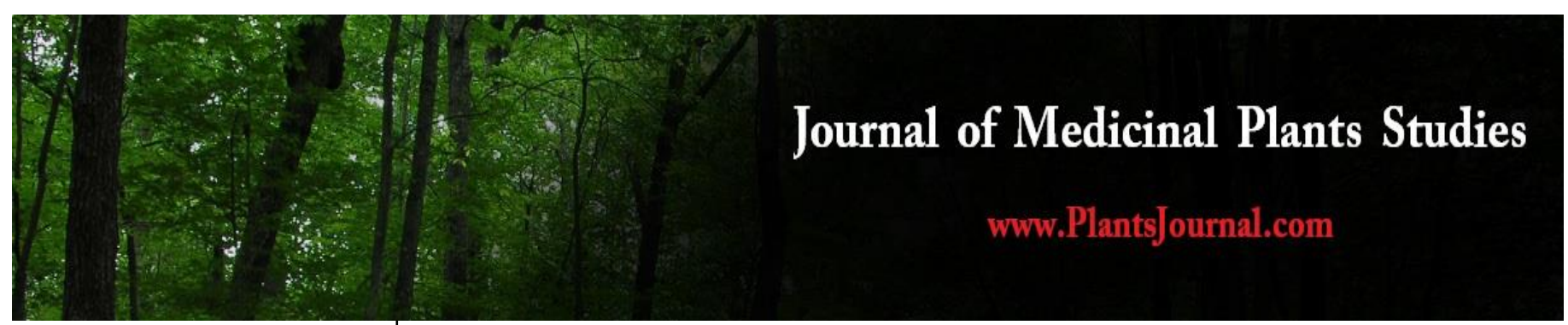

ISSN (E): 2320-3862

ISSN (P): 2394-0530

NAAS Rating: 3.53

JMPS 2018; 6(4): 36-40

(C) 2018 JMPS

Received: 08-05-2018

Accepted: 09-06-2018

Renu Joshi

Director, Study of Plants. Com

Trumbull, CT, USA

\section{Tripartite plant microbe and nutrients interaction in the below ground soil ecosystems}

\section{Renu Joshi}

\section{Abstract}

Plants are the sole producers that support all the trophic levels and sustain life on earth. In their growth and development, plants interact with both biotic and abiotic factors. The major biotic factors are the below ground microbes though there also above grown microbes and other herbivores. The abiotic factors are mainly the soil nutrients, soil temperature, moisture and light intensity. This paper therefore aimed at reviewing the various interactions within the soil rhizosphere especially between the plant roots interaction with soil microbes and how they are affected by the soil nutrient availability. The review focussed on identifying the major soil microbes in the soil rhizosphere, interaction of the plant roots with these microbes and how the interactions bring about nutrient cycling as well as dynamics in the trophic levels. From the review it came out clearly that plants interact with both pathogenic and non-pathogenic microbes resulting to varied results. Symbiotic relationship among plant roots and nitrogen fixing bacteria and mycorrhizal fungi results in improved plant growth and yields while interaction with pathogenic soil microbes resulted in disease development and reduced yield. Plants react to soil microbes by producing defensive secondary metabolites like phenolics. From the interaction some of the pathogenic microbes have developed mechanisms of evading the effects of plant defensive compounds by modifying them into forms that are less toxic. The review also shows that plant microbe interaction affects nutrient cycling and is also affected by the nutrients availability. The tripartite interaction of soil microbes, soil abiotic factors and plant root affects the general trophic levels in almost the entire ecosystems.

Keywords: Soil, soil microbes, soil nutrients, soil abiotic factors, plant roots, trophic levels

\section{Introduction}

Plants are the primary producers in the food chains and play a critical role in sustaining life on earth. Plants are the second largest source of energy after the sun. They have the ability to convert the solar energy to chemical energy that drive the most of the physiological and metabolic processes in almost all living organisms. Plants exist in varied ecosystems and interact with varied organisms ranging from antagonistic organisms to protagonistic or beneficial organisms (Pieterse et al., 475) ${ }^{[24]}$. In the varied ecosystems plants also interact with different forms of abiotic factors that either positively or negatively affect their growth and development. Some of the abiotic factor that the plants interact with include, air, moisture, space, temperature, light and soil (nutrients) (Erb and Lu, 1295-1303) ${ }^{[5]}$.

Interaction of plants with beneficial below ground microorganisms are very common and widely studied (Pieterse et al., 475) ${ }^{[24]}$. Most of these beneficial microorganisms develop symbiotic relationship with plants thus improving plant growth and also enabling the plants to boost their defensive mechanisms against biotic stress (Dutta, Mishra and Kumar, 452-461) ${ }^{[4]}$. The mutualistic relationship of the plants with these microbes also help in curbing other problems as a result of abiotic stresses. For instance, plants and mainly from the legume family have been known to symbiotically interact with rhizobium species which help in biological nitrogen fixation hence help in controlling the issues of the declining in the soil fertility factors (Hungria, Rubens and Ieda, 88-93) ${ }^{[13]}$. Despite the beneficial effects there, some of the reports indicate that some of these symbiotic microorganisms may also lower the plants immunity against pathogenic microorganisms (Mithöfer, 440-444) ${ }^{[19]}$.

In the soil, rhizosphere plants also interact with pathogenic microbes which have parasitic relationship. These microorganisms infect the plants extracting nutrients and in long run causing various diseases and harm to the plants community. The plant pathogenic microbes comprise of bacteria, fungi, viruses and nematodes. These microbes infect and affect plant growth and development in various ways.
Correspondence

Renu Joshi

Director, Study of Plants. Com

Trumbull, CT, USA 
For instance Fusarium oxysporum is a soil borne fungi that infect most of the Solanaceae family and at long rung may lead to the death of the plants (Inami et al., 200-210) ${ }^{[15]}$.

To counter the infection and effects of the pathogens plants have developed defensive mechanisms. Plant defence mechanisms involve complex signalling molecules that enable identification of the pathogen and triggering production of defensive compound such as phenolics, volatiles organic compounds and organic acids (Pieterse et al., 475) ${ }^{[24]}$. This review therefore aimed at identifying the issues on below ground microbial diversity, plant microbe interaction, patterns of nutrient dynamics and the plant microbe trophic dynamics.

\section{Below ground microbial diversity}

There is a huge population of microbial communities inhabiting the soil rhizosphere. Most of the soil microorganisms are bacteria, fungi and nematodes (Bagyaraj et al., 198-202) ${ }^{[1]}$. Some of the insect form part of the soil organism's diversity. These microbes interact with their environment in varied ways. Some of them have beneficial effects to their environment while others have destructive (parasitic) effect hence can be classified as either pathogenic or non-pathogenic microbes depending on how they interact with the plants and their close environs.

\section{Non-pathogenic microbes}

These are microbes that have symbiotic interaction with the plants and their other close environment. They interact with their environment to obtain nutrients for their growth and reproduction and in the process they contribute positively to the environment. Most of the beneficial association has been reported on root colonizing plant growth promoting rhizobium bacteria and mycorrhizal fungi (Pieterse et al., 475) [24]. Mycorrhizal fungi are the most common symbiotic having been reported to be able to associate with more than $80 \%$ of the total plant species in almost all ecosystems in the world

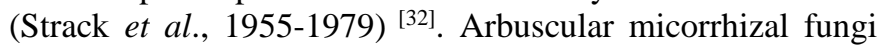
(AM) and ectotomycorrhizas are the two main types of mycorrhizas. AM mainly colonizes angiosperms, gymnosperms, mosses, lycopods and pteridophytes while ectotomycorrhizas associate with woody trees and shrubs. Recent studies have indicated existence of new species mycorrhizal fungi called ericoid mycorrhizas which is more specialized and found in areas with high organic material (Perotto, Girlanda, and Martino, 41-53) [23]. Other species of mycorrhizas that have been documented include Glomus mosseae, G. intraradices, Gigaspora rosea, Gaeumannomyces graminis and Drechslera sp (Strack et al., 1955-1979) ${ }^{[32]}$.

Plant growth promoting rhizobium bacteria are the second most studied beneficial belowground microbial organism. Rhizobium species have been studied and exploited due to its symbiotic interaction with the host plant leading to biological nitrogen fixation (Samac and Graham, 582-587) ${ }^{[28]}$. There are different species of rhizobium bacteria affecting many species of plants in almost all ecosystems. Most the bacteria species are host specific though a few have more than one host. For instance, Rhizobium leguminosarum colonizes Phaseolus vulgaris. Rhizobium meliloti hosted by clovers, Rhizobium trifolii infectsclovers, Trifolium spp, Bradyrhizobium japonicum Cow pea, (Vigna unguiculata), Rhizobium fredii Soybean, (Glycine max) and Rhizobium lupine lupine, Lupinus spp (Young et al., 89-103; Delestre et al., 121) ${ }^{[36,3]}$.

\section{Pathogenic microbes}

Apart from the beneficial microbes the other larger portion of the belowground microbes are composed of pathogenic microbes that do more harm to the plant growth development and reproduction. Most of the pathogenic microbes range from bacteria, viruses, oomycetes, protozoans, fungi and nematodes (Raaijmakers et al., 341-361; Figure 1) ${ }^{[26]}$. Out of these fungi, oomycetes and nematodes are considered as the major soil borne pathogenic microbes. Fungi and oomycetes are the most soil borne pathogen in all ecosystems on earth. Both have similar morphology where they are filamentous and multicellular organisms. They reproduce through spores. They are also heterotrophic in nature and absorb nutrients from host plants by the help of specialized hyphae called the mycelium (Raaijmakers et al., 341-361) ${ }^{[26]}$. Some the examples of the pathogenic plant fungi inhabiting the soil are Fusariun oxysporum, Verticillium dahlia, Pythium aphanidermatum, Colletotrichum lindemuthianum, Rhizoctonia solani, Sclerotium rolfsii and Trichoderma species (Kutateladze, 227-232) ${ }^{[16]}$. Nematode are free living worm like soil organisms. The survive by parasitizing plants and also consuming other soil organisms such as bacteria and fungi (Raaijmakers et al., 341-361) ${ }^{[26]}$.

Very few bacteria and viruses are soil borne and they require vectors to infect the plants. Some the bacteria that have been found in the soil rhizosphere and infecting the plants are Agrobacterium tumefaciens causing crown galls, Ralstonia solonanacearum, causing bacterial wilt and Streptomyces species (Genin and Boucher, 107-134; Raaijmakers et al., $341-361)^{[10,26]}$.

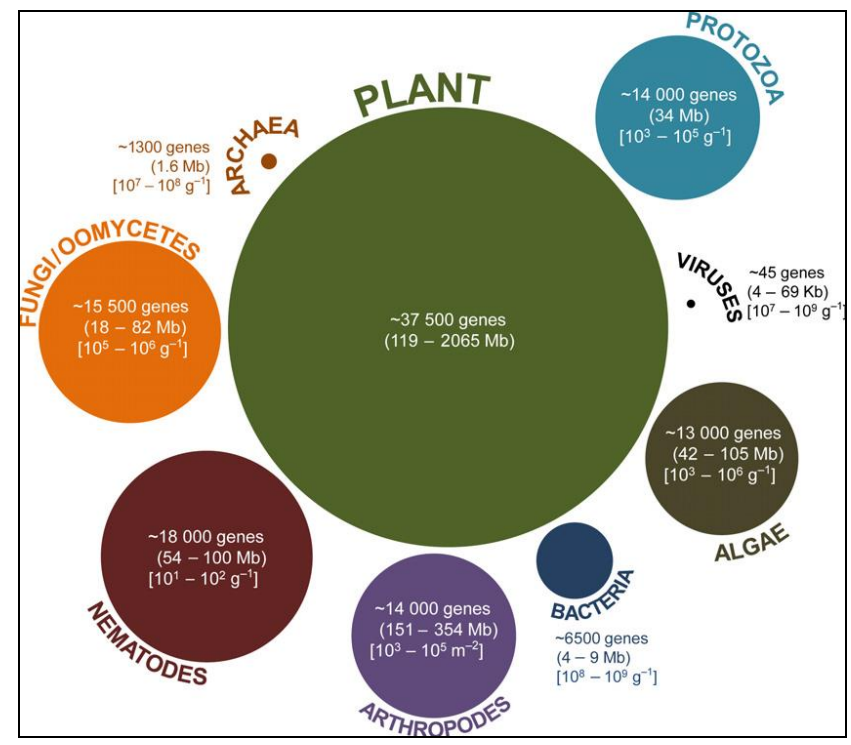

Fig 1: Overview of below ground soil microorganism's interaction with plant roots (source Mendes, Garbeva and Raaijmakers, 634663) ${ }^{[18]}$

\section{Plant microbe interaction}

The soil rhizosphere offers a hot spot for plant microbe interaction. The rhizosphere harbours various microbes covering both the beneficial and the pathogenic microbes. Most of the below ground microbes that interact with the plant roots are the bacteria, fungi, oomycetes, and nematodes (Raaijmakers et al., 341-361) ${ }^{[26]}$. Existence of the plant roots in the soil rhizosphere makes the environment conducive for microbial survival and interaction. This is because plant roots release exudates that are source of nutrients for soil microorganisms. Some of the exudates isoflavanons, luteolins and naringenin acts as chemoattractants to the soil microbes (Gage, 280-300) ${ }^{[7]}$. In the soil rhizosphere plants interact with both the pathogenic and non-pathogenic microorganism. The 
interaction may act additively improving plant uptake of nutrients or may also bring about competition for nutrients and other resources leading to the harming of the plants (Sabannavar and Lakshman, 2122-2133) ${ }^{[27]}$.

\section{Plant interaction beneficial microbes}

Some of the beneficial microbes that have positively interacted with plant are the plant growth promoting bacteria as the help in fixing the free air nitrogen to nitrates. With the help of Nod factors and polysaccharide signals, these bacteria enter the legume plants through root hair, sites of lateral root emergence or directly through the epidermis after which they induce nodule formation sites for biological nitrogen fixation. After entry, rhizobia multiply and differentiate into bacteroids in the nodules where they carry out dinitrogen fixation to ammonia $\left(\mathrm{NH}_{3}\right)$ and later to ammonium $\left(\mathrm{NH}_{4}{ }^{+}\right)$and nitrate $\left(\mathrm{NO}_{3}{ }^{-}\right)$forms that can be taken up by plants (Soto et al., 31673174) ${ }^{[31]}$. In the process of interaction, the bacterial also obtain nutrients from the plants for its growth and development. The other beneficial soil microbes are the mycorrhizas which are classified as the most important mutualistic symbioses on earth. Arbuscular mycorrhizas (AMs) being the most common (Bagyaraj et al., 198-202) ${ }^{[1]}$. AM fungi penetrating the plant cuticle into the root cortex by the help of intracellular hyphae which further differentiate into arbuscules. The arbuscules play a critical role in nutrient exchange between the host plants and the fungi. The nutrients flow is composed of carbohydrates transport from the host plant to the fungi and phosphates from fungi to the host plants (Bagyaraj et al., 198-202) ${ }^{[1]}$. Existence of AM fungi in the soil rhizosphere therefore makes phosphorus available for the plants.

\section{Interaction with pathogenic microbes}

Just like beneficial microbes the plants also interacts with pathogenic microbes resulting in mixed reactions. Plant pathogenic microbes attack and infect the host plants using various mechanisms such as production of macerating enzymes (Peeran at al. 295-300) ${ }^{[22]}$. Fungi use multi stage biotrophic- necrothrophic technique to gain access in the plants to multiply and cause death of the plants (O'Connell et al. 1060) ${ }^{[21]}$. Others secrete protein effectors that reprogram host cell immunity thereby facilitating infection. Once they have gained access in the plant the pathogenic microbes multiply using the host nutrients. The colonize the host cell leading to the development of disease symptoms and latter death. plants react to the effect of pathogenic microbes by production of secondary metabolites which are basically the defensive compounds against pathogens (Siupp and Bailey 101-112) ${ }^{[30]}$. Some of the secondary metabolites that have defensive mechanisms include majorly the phenolics comprising of phytoalexins phaseolin, phaseolidin, phaseolinisoflavan, kievitone, merdicarp and pisatin (Heath 77-90; Siupp and Bailey 101-112) ${ }^{[12,30]}$. These compounds are released by the host plants mainly on the infected areas. The compounds reduce severity of pathogen through disruption of spores and the hyphal contents mainly for the fungal pathogens (Bailey 1789-1791) ${ }^{[2]}$. Other secondary metabolites that confer resistance against the pathogenic microbes are the volatile organic compound for instance methyl salicylate and methyl jasmonate as they help in limiting conidial germination of the pathogenic fungi (Quintana-Rodriguez et al. 250-260; Neri et al. 30-35) ${ }^{[25,20]}$.

More interactions have shown that some pathogenic microbes have evolved survival mechanisms against the plant defensive compound. For instance, plant interaction with Colletotrichum species have seen them modifying plant antimicrobial metabolites to forms that are less harmful and enabling them to successfully colonize the host plants (van den Heuvel and van Etten 327-339; Bailey and Vincent 1789-1791) ${ }^{[34,2]}$. C. lindemuthianum, Fusarium solani ff.spp. phaseoli and Botrytis cinerea have been documented to be able to convert the phytoalexin phaseollin into 6a-hydroxyphaseollin and 7dihydroxyphaseollin; (van den Heuvel and Glazener 125-137) [35].

\section{Plant microbe interaction and nutrient dynamic patterns}

Nutrient availability is an important controller of plant species growth and development. The condition is affected by interaction of both biotic and abiotic factors (Eviner and Firestone, 94-106) ${ }^{[6]}$. Abiotic factors have been documented to influence plant microbe interactions in a number of ways. For instance, nutrient dynamics directly affects the diversity and distribution of belowground microbes and insects (Lepage et al., 159-165) ${ }^{[17]}$. Nematodes population and occurrences have been reported to be high in soils with low nitrogen (Gebremikael et al., 32862) ${ }^{[9]}$ while the functioning of the nitrogen fixing bacteria is mainly affected by the nitrogen content in the soil (Samac and Graham, 582-587) ${ }^{[28]}$. Nutrient dynamics in the root rhizosphere affects the plants physiology. Sufficient availability of nutrients in the soil ensures proper plant growth and also boost the plant immunity against belowground and aboveground pests (Gao, Chao and Lin, 742- 750) ${ }^{[8]}$. Plant microbe signalling is indirectly affected by availability of soil nutrients. Potassium (K) deficiency has been found to increase jasmonate and glucosinolates signalling molecules (Troufflard et al., 172) [33]. Plant microbe interaction also affects the distribution and availability of nutrients in the soil rhizosphere (Gebremikael et al., 32862) [9]. For instance interaction of plant growth promoting bacteria with leguminous plants helps in replenishing the soil nitrogen through biological nitrogen fixation (Samac and Graham, 582-587) ${ }^{[28]}$. Existence of AM fungi have been associated with making phosphorous available to the plants (Bagyaraj et al., 198-202) ${ }^{[1]}$. Soil microbes play an important role in conversion of organic matter to nutrient forms that can be taken up by the plants (Gebremikael et al., 32862) ${ }^{[9]}$. Plant microbe interaction also affect nutrient uptake by the plants. Nematodes infestation has been found to increase plant growth and nutrient uptake mainly in soils rich with nitrogen and organic matter (Gebremikael et al., 32862) ${ }^{[9]}$.

\section{Plant-microbe interaction and trophic dynamics}

A tripartite interaction among plant-microbe and soil abiotic factors my influence the diversity and distribution of soil microorganisms and their natural enemies (Erb and Lu, 12951303) ${ }^{[5]}$. Soil abiotic factor are the major players in the tritrophic dynamics through a number of ways. Nutrient availability determines production of signalling molecules (Ibrahim et al., 97-107) ${ }^{[14]}$. For instance potassium (K) deficiency has been found to increase jasmonate and glucosinolates signalling molecules (Troufflard et al., 172) [33]. Water which is also an abiotic factor determines the diffusion of the volatile compound in the soil while the soil structure determines the movement of natural enemies in the soil in reaction to the signalling molecules (Grant and Villani, 80-87). The interaction brings about the balance of nature in that it controls the population of the soil microbe in relation to their natural enemies. The extremes may also occur in that 
population of one group may increase to the level resulting to the extinction of the other organisms (Schulze and Harold, 497-510) ${ }^{[29]}$. Therefore completion by infection and predation among the soil microbes determines the most predominant species in the soil rhizosphere.

\section{Conclusion}

Rhizosphere offers conducive ground for plant interaction with the below ground pathogenic and pathogenic microbes. Soil abiotic factors are the main players in the plant microbe interaction in the soil. Nutrients availability is the major determinant in the production of signalling molecules by the plant roots. The signalling molecules are like jasmonate acids, flavonoids are the ones used by microbes to identify the plant roots, penetrate and cause infections. Signalling molecules are also used by natural enemies to identify soil microbes. From the researches it is clear that the tripartite interaction of soil microbes, soil abiotic factors and plant roots lead to changes in the diversity and distribution of soil microorganisms, it also brings about the changes in the nutrient cycling as well as trophic levels dynamics. From the review of various researches, soil abiotic factors have proven to be the major players in plant microbe interactions. Abiotic factors should therefore be of great consideration in any development that involves the control of plant pathogenic microbes.

\section{References}

1. Bagyaraj DJ et al. Below ground microbial diversity as influenced by coffee agroforestry systems in the Western Ghats, India. Agriculture, Ecosystems \& Environment 2015; 202:198-202.

2. Bailey JA, Vincent GG. Metabolism of phaseollin by Colletotrichum lindemuthianum. Phytochemistry. 1974; 13(9):1789-1791.

3. Delestre Clément et al. Genome sequence of the clover symbiont Rhizobium leguminosarum bv. trifolii strain CC275e. Standards in genomic sciences. 2015; 10(1):121.

4. Dutta S, Mishra AK, Dileep Kumar BS. Induction of systemic resistance against fusarial wilt in pigeon pea through interaction of plant growth promoting rhizobacteria and rhizobia. Soil Biology and Biochemistry. 2008; 40(2):452-461.

5. Erb Matthias, Jing Lu. Soil abiotic factors influence interactions between belowground herbivores and plant roots. Journal of experimental botany. 2013; 64(5):12951303.

6. Eviner Valerie T, Mary Firestone K. Mechanisms determining patterns of nutrient dynamics. California Grasslands: Ecology and Management. 2007, 94-106.

7. Gage Daniel J. Infection and invasion of roots by symbiotic, nitrogen-fixing rhizobia during nodulation of temperate legumes. Microbiology and Molecular Biology Reviews. 2004; 68(2):280-300.

8. Gao Ji-Ping, Dai-Yin Chao, Hong-Xuan Lin. Understanding abiotic stress tolerance mechanisms: recent studies on stress response in rice. Journal of Integrative Plant Biology. 2007; 49(6):742-750.

9. Gebremikael Mesfin $\mathrm{T}$ et al. Nematodes enhance plant growth and nutrient uptake under $\mathrm{C}$ and $\mathrm{N}$-rich conditions. Scientific reports. 2016; 6:32862.

10. Genin Stéphane, Christian Boucher. Lessons learned from the genome analysis of Ralstonia solanacearum. Annu. Rev. Phytopathol. 2004; 42:107-134.

11. Grant Jennifer A, Michael Villani G. Soil moisture effects on entomopathogenic nematodes. Environmental
Entomology. 2003; 32(1):80-87.

12. Heath Michèle C. Hypersensitive response-related death. Programmed cell death in higher plants. Springer, Dordrecht, 2000, 77-90.

13. Hungria Mariangela, Rubens José Campo, Iêda Carvalho Mendes. Benefits of inoculation of the common bean (Phaseolus vulgaris) crop with efficient and competitive Rhizobium tropici strains. Biology and Fertility of Soils. 2003; 39(2):88-93.

14. Ibrahim MA et al. The influence of different nutrient levels on insect-induced plant volatiles in $\mathrm{Bt}$ and conventional oilseed rape plants. Plant Biology. 2008; 10(1):97-107.

15. Inami Keigo et al. The Tomato Wilt Fungus Fusarium oxysporum f. sp. lycopersici shares Common Ancestors with Nonpathogenic F. oxysporum isolated from wild tomatoes in the Peruvian Andes. Microbes and environments. 2014; 29(2):200-210.

16. Kutateladze LY et al. Microscopic fungi spread in different types of soils in Western Georgia. Annals of Agrarian Science. 2016; 14(3):227-232.

17. Lepage MP et al. Effect of soil temperature and moisture on survival of eggs and first-instar larvae of Delia radicum. Environmental entomology. 2012; 41(1):159165.

18. Mendes Rodrigo, Paolina Garbeva, Jos Raaijmakers M. The rhizosphere microbiome: significance of plant beneficial, plant pathogenic, and human pathogenic microorganisms. FEMS microbiology reviews. 2013; 37(5):634-663.

19. Mithöfer Axel. Suppression of plant defence in rhizobialegume symbiosis. Trends in Plant Science. 2002; 7(10):440-444.

20. Neri, Fiorella et al. Fungicidal activity of plant volatile compounds for controlling Monilinia laxa in stone fruit. Plant Disease. 2007; 91(1):30-35.

21. O'Connell Richard $\mathbf{J}$ et al. Lifestyle transitions in plant pathogenic Colletotrichum fungi deciphered by genome and transcriptome analyses. Nature genetics. 2012; 44(9):1060.

22. Peeran Mohammed Faisal, Prabakar Kuppusami, Raguchander Thiruvengadam. Pathogenesis of Colletotrichum lindemuthianum the incitant of anthracnose disease in beans mediated by macerating enzymes. The Bioscan. 2014; 9(1):295-300.

23. Perotto Silvia, Mariangela Girlanda, Elena Martino. Ericoid mycorrhizal fungi: some new perspectives on old acquaintances. Diversity and Integration in Mycorrhizas. Springer, Dordrecht, 2002, 41-53.

24. Pieterse Corné MJ et al. Induced plant responses to microbes and insects. Frontiers in plant science. 2013; 4:475.

25. Quintana-Rodriguez Elizabeth et al. Plant volatiles cause direct, induced and associational resistance in common bean to the fungal pathogen Colletotrichum lindemuthianum. Journal of Ecology. 2015; 103(1):250260.

26. Raaijmakers Jos M et al. The rhizosphere: a playground and battlefield for soilborne pathogens and beneficial microorganisms. Plant and soil. 2009; 321(1-2):341-361.

27. Sabannavar Shweta J, Lakshman HC. Synergistic Interactions among Azotobacter, Pseudomonas, and Arbuscular Mycorrhizal Fungi on Two Varieties of Sesamum Indicum L. Communications in soil science and plant analysis. 2011; 42(17):2122-2133. 
28. Samac Deborah A, Michelle Graham A. Recent advances in legume-microbe interactions: recognition, defense response, and symbiosis from a genomic perspective. Plant Physiology. 2007; 144(2):582-587.

29. Schulze E-D, Harold Mooney A. Ecosystem function of biodiversity: a summary. Biodiversity and ecosystem function. Springer, Berlin, Heidelberg, 1994, 497-510.

30. Siupp RA, Bailey JA. The fungitoxicity of isoflavanoid phytoalexins measured using different types of bioassay. Physiological Plant Pathology. 1977; 11(1):101-112.

31. Soto María J, Juan Sanjuan, Jose Olivares. Rhizobia and plant-pathogenic bacteria: common infection weapons. Microbiology. 2006; 152(11):3167-3174.

32. Strack Dieter et al. Arbuscular mycorrhiza: biological, chemical, and molecular aspects. Journal of Chemical Ecology. 2003; 29(9):1955-1979.

33. Troufflard, Stephanie, et al. Potassium deficiency induces the biosynthesis of oxylipins and glucosinolates in Arabidopsis thaliana. BMC Plant Biology. 2010; 10(1):172.

34. Van den Heuvel J, Van Etten HD. Detoxification of phaseollin by Fusarium solani f. sp. phaseoli. Physiological Plant Pathology. 1973; 3(3):327-339.

35. Van den Heuvel, Johannes, Judy Glazener A. Comparative abilities of fungi pathogenic and nonpathogenic to bean (Phaseolus vulgaris) to metabolize phaseollin. Netherlands Journal of Plant Pathology. 1975; 81(4):125-137.

36. Young JM et al. A revision of Rhizobium Frank 1889, with an emended description of the genus, and the inclusion of all species of Agrobacterium Conn 1942 and Allorhizobium undicola de Lajudie et al. 1998 as new combinations: Rhizobium radiobacter, R. rhizogenes, R. rubi, R. undicola and R. vitis. International Journal of Systematic and Evolutionary Microbiology. 2001; 51(1):89-103. 